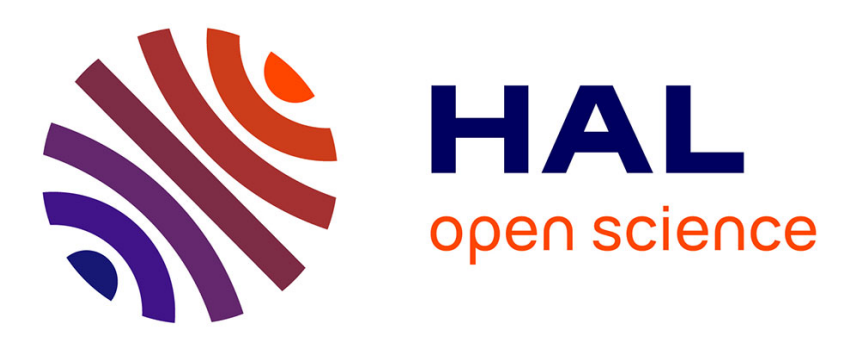

\title{
Radiation-hardened Erbium doped LMA fiber with AlP composition from solution doping process
}

\author{
G. Canat, J.K.S. Sahu, J. Le Gouët, L. Lombard, J. Nilsson, S. Duzellier, D. \\ Boivin, W. Renard
}

\section{- To cite this version:}

G. Canat, J.K.S. Sahu, J. Le Gouët, L. Lombard, J. Nilsson, et al.. Radiation-hardened Erbium doped LMA fiber with AlP composition from solution doping process. CLEO 2014, Jun 2014, SAN JOSE, United States. hal-01069689

\section{HAL Id: hal-01069689 \\ https: / hal-onera.archives-ouvertes.fr/hal-01069689}

Submitted on 29 Sep 2014

HAL is a multi-disciplinary open access archive for the deposit and dissemination of scientific research documents, whether they are published or not. The documents may come from teaching and research institutions in France or abroad, or from public or private research centers.
L'archive ouverte pluridisciplinaire HAL, est destinée au dépôt et à la diffusion de documents scientifiques de niveau recherche, publiés ou non, émanant des établissements d'enseignement et de recherche français ou étrangers, des laboratoires publics ou privés. 


\title{
Radiation-hardened Erbium doped LMA fiber with AIP composition from solution doping process
}

\author{
G. Canat ${ }^{1}$, J.K.S. Sahu ${ }^{2}$, J. Le Gouët ${ }^{1}$, L. Lombard ${ }^{1}$, J. Nilsson ${ }^{2}$, S. Duzelier ${ }^{1}$, D. Boivin ${ }^{1}$, W. Renard ${ }^{1}$, \\ Onera, The French Aerospace Lab., DOTA, Chemin de la Hunière, 91123 PALAISEAU Cedex, France \\ Optoelectronics Resaerch Center, University of Southampton, United Kingdom \\ guillaume.canat@onera.fr
}

\begin{abstract}
We report on Erbium doped large-mode-area fibers based on the phosphoaluminosilicates. The radiation induced attenuation are reduced compared to standard highly doped fibers. We measured $22 \%$ power conversion efficiency for core pumping at $1532 \mathrm{~nm}$. OCIS codes: (060.2290) Fiber materials; (060.2320) Fiber optics amplifiers and oscillators.
\end{abstract}

\section{Introduction}

Fiber lasers emitting around 1550nm have many applications as they are eyesafe, emit in a good atmospheric transparency window and can benefit from cheap fiber components. Erbium ions are used to amplify at these wavelengths but their concentration is limited in silica by clustering effects. In order to alleviate clustering a large amount of alumina must be incorporated into the silica. The standard process to prepare doped fibers is the solution doping MCVD. However in this process, the maximum Al concentration is limited by cristallization. For some applications such as space systems radiation induced attenuation (RIA) is also major issue. RIA is known to increase with the Al concentration and when impurities are present. Moreover high energy fiber systems require LMA fibers with low NA that are not compatible with large Al concentration. It was shown that the phosphoalumino silicate composition allowed to limit the core refractive index increase as the equimolar addition of alumina and phosphorous reduces the glass refractive index [1,2]. The best results were recently obtained using chelate compounds as precursors [2]. However this technology remains complex.

We report on the properties of Erbium doped LMA fibers based on a phosphoaluminosilicate composition produced by solution doping MCVD process. These fibers have a reduced radiation sensitivity compared to commercial Erbium fibers and comparable efficiency.

\section{Fibers properties}

Figure 1 left shows the EDS measurement on fiber A. In order to avoid crystallization issues, $\mathrm{P}$ concentration was kept relatively large compared to $\mathrm{Al}$ concentration. As previously reported the Al profile does not follows exactly the $\mathrm{P}$ profile. As the Er concentration target was relatively high and Al concentration was limited, we used $\mathrm{Yb}$ as a screening agent in order to reduce the Er clustering. The Erbium concentration reaches an average of $420 \mathrm{ppm}$ mol corresponding to the measured peak absorption of $45 \mathrm{~dB} / \mathrm{m}$. The evaporation of the phosphorous during the soot collapse explains the presence of the central dip. The refractive index profile was measured on the preform and compares well with the profile computed using the non additive relation IPHT and the RE contribution [2]. Figure 1 right shows the index profile of the fiber. It also features a central depression. Tapering the fiber input allows to keep a relatively good beam quality.
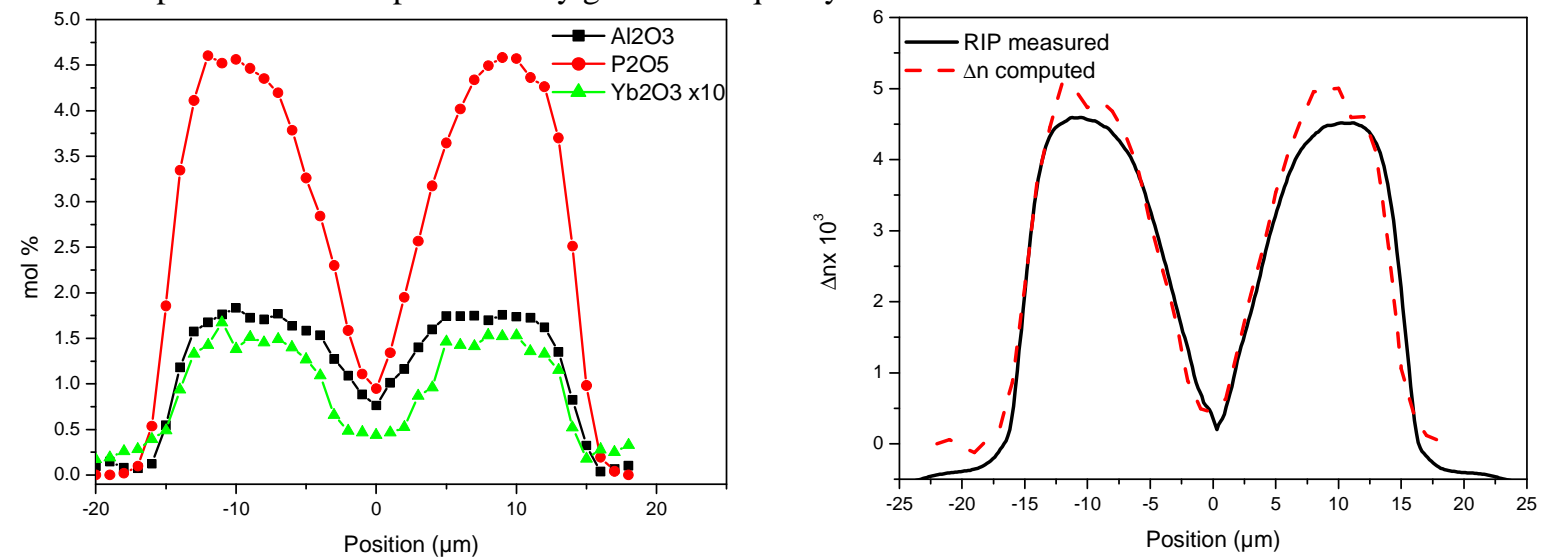

Fig. 1. Left: Chemical analysis of fiber A by EDS. Right: Measured refractive index on the preform (solide line) and calculted using the EDS concentration (dashed line).

Fibre B has a similar composition as fiber A with [Yb] increased by $30 \%$ and [Al] increased by $25 \%$ and was drawn with a core diameter of $30 \mu \mathrm{m}$ and core NA 0.12 . Fiber $\mathrm{C}$ has the same composition as fiber B but was drawn to $11 \mu \mathrm{m}$ core diameter. A length of $10 \mathrm{~m}$ of fiber $\mathrm{C}$ was $\gamma$-irradiated using a were ${ }^{60} \mathrm{Co}$-source at room temperature to check for the RIA. Using the same protocol fiber L (Er-40-4-125) from Liekki with 427 ppm 
Erbium was also irradiated. The radiation induced attenuation reaches a maximum of $0.15 \mathrm{~dB} / \mathrm{m}$ for fiber $\mathrm{C}$ and $0.68 \mathrm{~dB} / \mathrm{m}$ for fiber $\mathrm{L}$ around $1500 \mathrm{~nm}$ for a dose equal to $10 \mathrm{kRad}$. This reduction of RIA in the aluminosilicate host confirms recent results [3].

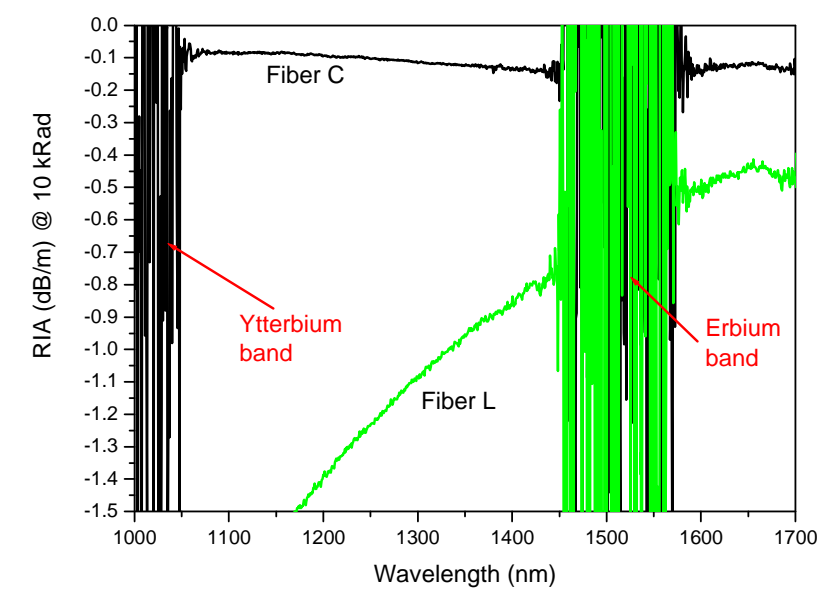

Fig. 2. Radiation induced attenuation losses on fiber C and fiber L (Liekki).

\section{Amplification experiments}

A CW amplifier was built to assess fiber B slope efficiency. A $1565 \mathrm{~nm}$ seed laser was splice to a fiber multiplexer to couple a $1532 \mathrm{~nm}$ pump fiber laser to a piece of fiber B of length L through a mode field adaptator. The output power and spectrum were recorded for various input power. For $\mathrm{L}=6.4 \mathrm{~m}$ and for $60 \mathrm{~mW}$ input power, the fiber is not saturated and the output power quickly saturates (cf. Figure 3). For $600 \mathrm{~mW}$ input power the output power increases steadily. The power conversion efficiency (PCE) reaches a maximum of $22 \%$ for $\mathrm{L}=5.3$ $\mathrm{m}(20 \%$ for $\mathrm{L}=6.4 \mathrm{~m})$. With a highly doped LMA fiber from Liekki (Er-60-40/140DC) manufactured using the DND process the PCE was measured to be $19.4 \%$ at this wavelength [4]. In both cases the PCE is limited by the presence of clusters partially reduced in the case of the Liekki fiber but the DND process and in the case of fiber $\mathrm{B}$ by the glass host and the presence of Ytterbium. For the Liekki fiber the fraction of paired ions was indeed estimated to be $8.2 \%$ [4] whereas we measured $5 \%$ for fiber $\mathrm{C}$ using unsaturable losses measurements.

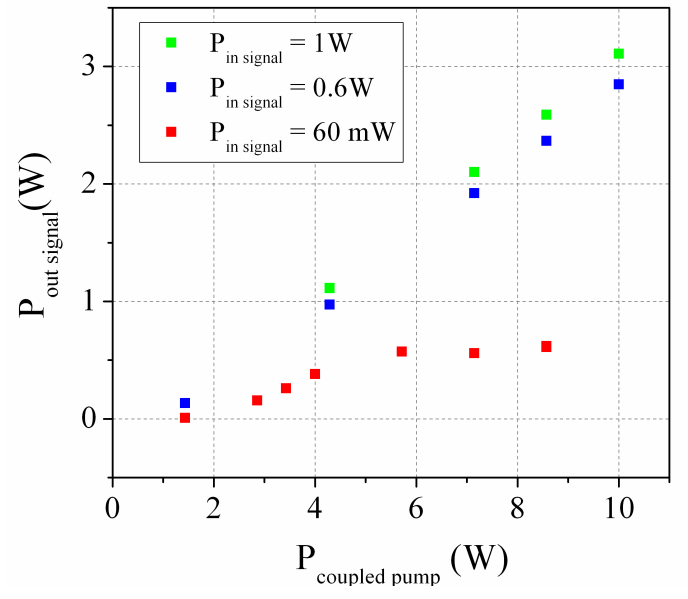

Fig. 3. Amplification results at $1565 \mathrm{~nm}$ for $\mathrm{L}=6.4 \mathrm{~m}$ of fiber $\mathrm{B}$.

Further comparison with fibers prepared using the gas phase technique and this solution doping technique should help determining the best technology for radiation resistant LMA fibers.

\section{References}

[1] Mikhail E. Likhachev, Mikhail M. Bubnov, Kirill V. Zotov, Denis S. Lipatov, Mikhail V. Yashkov, and Aleksei N. Guryanov, "Effect of the $\mathrm{AlPO}_{4}$ joint on the pump-to-signal conversion efficiency in heavily Er-doped fibers," Opt. Lett. 34, 3355-3357 (2009)

[2] Unger, Sonja, et al. "Codoped materials for high power fiber lasers: diffusion behaviour and optical properties." Integrated Optoelectronic Devices 2007. International Society for Optics and Photonics, 2007.

[3] Mikhail E. Likhachev, Mikhail M. Bubnov, Kirill V. Zotov, Alexander L. Tomashuk, Denis S. Lipatov, Mikhail V. Yashkov, and Alexey N. Guryanov, "Radiation Resistance of Er-Doped Silica Fibers: Effect of Host Glass Composition," J. Lightwave Technol. 31, 749-755 (2013)

[4] Ee-Leong Lim, Shaif-ul Alam, and David J. Richardson, "Optimizing the pumping configuration for the power scaling of in-band pumped erbium doped fiber amplifiers," Opt. Express 20, 13886-13895 (2012) 